\title{
Intergenerational effects of endocrine-disrupting compounds: a review of the Michigan polybrominated biphenyl registry
}

\author{
Sarah W Curtis ${ }^{1}$, Karen N Conneely ${ }^{1,2}$, Mary E Marder ${ }^{3}$, Metrecia L Terrell ${ }^{4}$, Michele \\ Marcus $^{3,4,5}$ \& Alicia K Smith*,1,6,7 \\ ${ }^{1}$ Genetics and Molecular Biology Program, Emory University, Atlanta, GA 30322, USA \\ ${ }^{2}$ Department of Human Genetics, Emory University, Atlanta, GA, 30322, USA \\ ${ }^{3}$ Department of Environmental Health, Rollins School of Public Health, Emory University, Atlanta, GA, 30322, USA \\ ${ }^{4}$ Department of Epidemiology, Rollins School of Public Health, Emory University, Atlanta, GA, 30322, USA \\ ${ }^{5}$ Department of Pediatrics, Emory University School of Medicine, Atlanta, GA, 30322, USA \\ ${ }^{6}$ Department of Gynecology and Obstetrics, Emory University School of Medicine, Atlanta, GA, 30322, USA \\ ${ }^{7}$ Department of Psychiatry and Behavioral Sciences, Emory University School of Medicine, Atlanta, GA, 30322, USA \\ *Author for correspondence: alicia.smith@emory.edu
}

Endocrine-disrupting compounds (EDCS) are a broad class of chemicals present in many residential products that can disrupt hormone signaling and cause health problems in humans. Multigenerational cohorts, like the Michigan polybrominated biphenyl registry, are ideal for studying the effects of intergenerational exposure. Registry participants report hormone-related health problems, particularly in those exposed before puberty or those in the second generation exposed through placental transfer or breastfeeding. However, more research is needed to determine how EDCs cause health problems and the mechanisms underlying intergenerational exposure. Utilizing existing data in this registry, along with genetic and epigenetic approaches, could provide insight to how EDCs cause human disease and help to determine the risk to exposed populations and future generations.

First draft submitted: 20 December 2017; Accepted for publication: 16 March 2018; Published online: 11 June 2018

Keywords: environmental epigenomics $\bullet$ epigenetic effects $\bullet$ epigenetic epidemiology

Endocrine-disrupting compounds (EDCs) are a broad class of chemicals that can disrupt hormone signaling by interfering with steroidogenesis, receptor binding or hormone homeostasis. They are ubiquitous in the environment, found in many industrial and residential settings, and can even be found in seemingly innocuous substances, like household dust [1]. However, the health effects of EDCs are not fully known. Adding to the need to research the effects of EDC exposure, EDC-associated health effects are observed in the children of those exposed, suggesting an intergenerational transmission of health risk [2-5].

The Michigan polybrominated biphenyl (PBB) registry is a unique, multigenerational cohort of individuals exposed to high levels of a single type of EDC, which may provide insight into the effects of EDCs on humans. Registrants were exposed to PBB during an agricultural accident in the 1970s, and they and their children have been followed for the past 40 years. Many individuals still have detectable levels of PBB in their blood. This review will focus on the potential mechanisms through which $\mathrm{PBB}$ exposure may lead to intergenerational health risks, drawing on the background of the contamination incident, the existing studies on the known health effects and existing genetic and epigenetic studies from other types of EDCs.

\section{The Michigan incident}

Flame retardants have been used in electronic appliances, textiles, plastics and polyurethane foams since the increase in fire safety legislation in the 1960s, with one of the most common flame retardants being PBB. From 1970 to 1976 alone, 13.3 million pounds of PBBs were produced in the USA. Over $88 \%$ of all PBBs were produced by 
Velsicol's Michigan Chemical Company as FireMaster BP-6 and FireMaster FF-1 [6]. In May 1973, a shipment of FireMaster FF-1 was mistakenly shipped to Farm Bureau Services feed mill instead of NutriMaster (magnesium oxide), a nutritional supplement for livestock feed. Both substances were produced by the Michigan Chemical Company, both were fine white powders, and both were stored in plain bags with black lettering [7]. It is not known how much FireMaster FF-1 was sent to the Farm Bureau, but the estimates range from 500 to 1000 pounds [8].

In July 1973, the Farm Bureau mixed the FireMaster FF-1 into their animal feed, and during that fall, contaminated animal feed with high levels of PBBs (4000-13,500 ppm) was shipped to farms around Michigan [7,8]. The contaminated feed was no longer on the market by December 1973, but animals were fed with it until May 1974, when PBB was identified as the cause of the toxic effects seen in the farm animals $[7,8]$. Additionally, lower levels of contamination still occurred from several sources. Mill machinery still contained PBB residues and continued to contaminate new animal feed. One mill alone contaminated over 3000 pounds of feed in this manner. Feed swapping between mills and recycling contaminated animals products for new animal feed added to the number of mills and animals that were contaminated [8]. This caused a lower level of contamination, but it continued until the mills were cleaned a year later $[7,8]$.

After the introduction of feed contaminated with high concentrations of PBB at dairy farms across Michigan, cows' feed consumption decreased by $50 \%$, followed by a decrease in milk production. Cows also had difficulties reproducing and calving, had abnormal hoof growths, hyperkeratosis and hematomas. Abscesses were found on the dead cows' livers and other organs, as were intra-abdominal adhesions $[9,10]$. Cattle were underweight, had fibroids in their lungs, enlarged thymus glands and lesions and lymphocyte infiltration in their livers and kidneys. The bulls had a reduced number or complete lack of mature spermatozoa and atrophied testes. Furthermore, the small intestine showed lymphocyte infiltration, which may explain the decreased feed consumption [10].

With the cause of the health problems in the livestock finally identified as the contaminated feed, efforts focused on stopping the contamination from spreading. The US FDA regulated that PBB levels must be less than $1 \mathrm{ppm}$ in dairy products intended for human consumption. The Michigan Department of Agriculture identified and quarantined contaminated farms. Although the quarantine started with dairy farms, other livestock had to be quarantined because of the cross contamination at the Farm Bureau mills. Over 30,000 cattle, 2000 pigs, 400 sheep and 2 million chickens had to be destroyed and buried in state-approved burial sites [7].

Given the toxic effects observed in exposed animals, human exposure to PBBs was a concern. It was determined that approximately 6.5 million people in Michigan had some $\mathrm{PBB}$ exposure, with higher exposures among those who lived on quarantined farms or worked at the Michigan Chemical Company [7,8,11]. In the mid-1970s, approximately 5000 individuals consented to participate in a study of the long-term effects of PBBs on humans (Figure 1). Many of the registrants' children have since been enrolled [8].

\section{Biochemistry of PBBs}

PBBs are a class of chemicals characterized by two phenyl rings with bromine substitutions. The number and positions of the bromine substitutions yield 209 different configurations of $\mathrm{PBB}$, called congeners. The chemical properties and biological activity of PBB depend on the degree and position of the substitution [6]. The commercial product in the Michigan incident was FireMaster FF-1, which consisted of another existing technical mixture of PBBs (FireMaster BP-6) and 2\% calcium silicate - an anticaking agent [7]. Twenty-two different congeners of PBBs have been detected in FireMaster BP-6, with the most common congeners being PBB-153 (2,2',4, $4^{\prime}, 5,5^{\prime}$ -

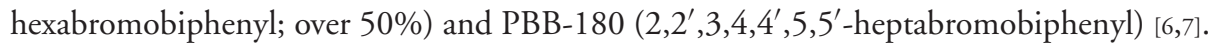

\section{Effects of PBBs in animal models}

Studies showed that pregnant cattle fed 25,000 mg ( 3250 ppm) of FireMaster BP-6 a day ate less food, became emaciated, had diarrhea, had excessive salivation and miscarried. Much like the cows on the contaminated farms, exposed cattle also had depressed heart and respiratory rates, and died after about 1-2 months of exposure [12]. Cows that were fed $100 \mathrm{mg} /$ day $(\sim 13 \mathrm{ppm})$ of PBBs had lacrimation, hyperkeratosis, alopecia, elevated lymphocytes, decreased milk production and lesions of the kidneys, liver and skin [13]. Male calves who were exposed had degeneration in the epithelial lining of their seminiferous tubules [13]. Further studies in 60 dairy cattle showed that PBBs were absorbed in the GI tract and could be detected in the bloodstream mere hours after ingestion. PBBs are concentrated in lipid-rich tissue, with adipose tissue in the cows fed $1125 \mathrm{~g}$ of PBB having a concentration of $1836 \mathrm{ppm}$, versus $267 \mathrm{ppm}$ in the liver and $53.3 \mathrm{ppm}$ in blood plasma. Calves born to exposed cows were also 


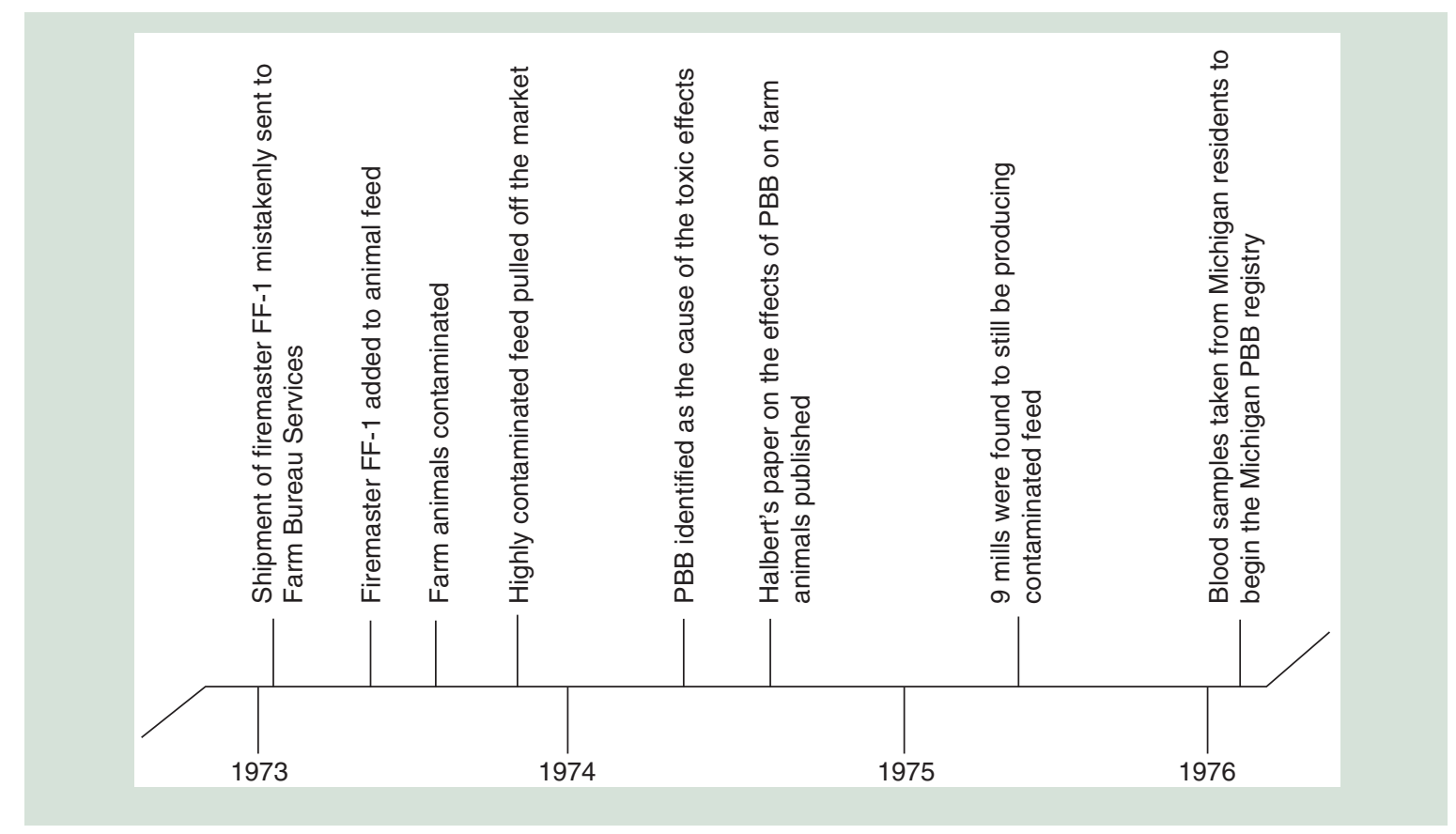

Figure 1. Timeline of the Michigan incident.

exposed through placental transfer and nursing and had PBB concentrations with similar tissue distribution as those exposed through eating contaminated feed [13,14].

Because many chickens became sick after eating cross-contaminated animal feed during the initial event in Michigan, the effect of PBBs on chickens was studied. Chickens starved rather than eat a diet high in PBBs and had a reduced feed intake when fed a diet that had low concentrations of PBBs. Once exposed, the PBB levels in their adipose tissue remained unchanged over the 2-month study. Exposed chickens had reduced egg production (66\% decrease) and those eggs had reduced hatchability, although, part of that could be due to the reduction in food intake [15].

Research was also done in traditional animal models. Much like the exposed cows, rats and their pups who were fed high levels of PBBs (200 ppm) weighed 15\% less and had delayed growth compared with controls [16]. Pregnant rats fed $\mathrm{PBBs}$ had detectable concentrations of $\mathrm{PBB}$ in their brain, heart, lung, liver, small intestine, placenta, uterus, kidneys, skin, mammary tissues and fat, with the fat and mammary tissues having the highest concentrations of PBB (965 and 500 ppm, respectively) [16,17]. Rat pups who were nursed by PBB-exposed rats had higher PBB levels than did the rat pups who were only exposed in utero (68.6-149.7 vs 1.6-5.4 ppm), suggesting that, while $\mathrm{PBBs}$ do cross the placental barrier and expose the fetus, nursing was a significant mechanism of intergenerational exposure [17].

PBB-exposed rats and their offspring (exposed either in utero or through breastfeeding) have larger livers for their bodyweight (12.4 vs $10.3 \mathrm{~g}$ ), and the offspring weighed less (10 vs $14 \mathrm{~g}$ at 6 postbirth) compared with control rates. Additionally, $64 \%$ of the offspring of PBB-exposed rats did not have detectable vaginal opening by day 46, versus $100 \%$ of the offspring of control rats $[18,19]$. Rat pups who were exposed, both prenatally and perinatally, and then weaned onto a PBB-free diet still show residual effects from PBB exposure 10 months later. Specifically, the liver was larger and had larger vacuoles, a response that is seen with exposure to other hepatotoxicants. This increased vacuolation was most prominent soon after exposure. The livers of exposed rat pups also had retained bile, slight necrosis and cellular swelling [20].

Besides the overt physical changes, rats exposed to PBBs have altered enzyme activity compared with control rats. They showed increased microsomal enzyme activity in both the liver and kidneys [20,21]. Both pregnant rats and their offspring had a tenfold increase in AHH activity and threefold increase in EH activity in their livers. The rats had increased $\mathrm{AHH}$ activity in their kidneys and mammary glands and decreased $\mathrm{EH}$ activity in their mammary glands [16,21], as well as increased activity of cytochrome P-450 and its associated enzymes [22]. 
AHH activates cytochrome P-450, which is important for the synthesis of steroid hormones and fat molecules, and $\mathrm{EH}$ and cytochrome P-450 both play a role in the metabolism of xenobiotic and toxic compounds. AHH activity was higher $(237.48$ vs $118.88 \mathrm{U} / \mathrm{mg} / \mathrm{min}$ ) when the rats were exposed to $\mathrm{PBBs}$ than when they were exposed to polychlorinated biphenyl (PCB), another EDC, suggesting that PBBs had more of an effect on the liver and kidneys [16]. The authors mentioned that exposure to dioxin, a well-known lipophilic carcinogen and environmental pollutant, caused a similar increase in $\mathrm{EH}$ activity, but in the rats' lung and skin tissue, suggesting that PBB, like PCB, could be dioxin-like [21]. Offspring of rats exposed to $100 \mathrm{ppm}$ diet metabolized the anesthetic, pentobarbital, more quickly (duration was only $1 \%$ that of controls) and had 57\% less vitamin A in their livers, suggesting that $\mathrm{PBB}$ exposure can affect the metabolism of naturally occurring compounds and xenobiotics for an extended period $[19,20]$. Further, the different congeners of PBB induce different responses in rat livers. One congener tested had no effect on liver enzymes, two others, including the second most common congener in both FireMaster mixtures, PBB-180, had a strictly phenobarbital-type induction on liver enzymes, and another congener had a mixed (both 3-methylcholanthrene- and a phenobarbital-type) induction on liver enzymes, indicating that different congeners will induce different series of enzymes [23,24]. Therefore, the specific congener composition of the PBB mixture will determine the effects for humans and animals.

PBB exposure also affected hormone homeostasis. Rats who were directly fed low levels of PBBs had decreased levels of serum $T_{4}$ and $T_{3}$. These hormone levels in exposed rats had a smaller increase than control rats when administered a dose of thyroid-stimulating hormone [25]. Rats who were exposed to PBBs had increased metabolism in the liver of both progesterone (to $16 \alpha$ - and $6 \beta$-hydroxyprogestrone) and testosterone (to $7 \alpha$ - and $6 \beta$ - hydroxytestosterone) as measured using high-performance liquid chromatography followed by gas chromatography-mass spectrometry $[19,26,27]$. Additionally, PBB exposure reduced the metabolism of testosterone to dihydrotestosterone and dihydroandrosterone [27]. This suggests that PBB induces multiple steroid enzymes and that the fertility and developmental problems in exposed animals could be caused by this altered steroid hormone metabolism. Even the $\mathrm{F}_{2}$ generation showed effects of $\mathrm{PBB}$ exposure, such as rapid metabolism of progesterone and pentobarbital, indicating that intergenerational transmission of PBB carries health risks [19].

Studies were also conducted in nonhuman primates. Seven rhesus monkeys were fed 0.3 ppm PBB over 6 months to simulate the estimated exposure levels in Michigan. All of the animals lost an average of $7.4 \%$ of their body weight over the course of the experiment, despite being fed the same amount, indicating that PBB exposure altered nutritional absorption and that the weight loss seen in the farm animals in Michigan was not caused solely by a decrease in food intake. They also reported sterile abscesses (abscesses not caused by bacteria), increased menstrual cycle length (31 vs 28 days) that was associated with a longer, flatter progesterone peak and excessive implantation bleeding (12-16 days) and miscarriages. Live offspring were smaller and gained weight slower through 3 months compared with unexposed controls. Monkeys fed $25 \mathrm{ppm}$ PBB had inflamed stomachs as well as enlarged liver cells [28]. Further studies in CV-1 cell lines (derived from African green monkey kidney cells) also demonstrated PBB's effect on hormone receptors. PBBs suppressed thyroid hormone receptor-mediated transcription (45\% of $\operatorname{TR} \beta 1$ and $65 \%$ of TR $\alpha 1$ ), which in turn, suppressed thyroid hormone induced dendrite branching. Based on these results, PBBs could not only impair hormonal balance, but could also impair neuronal development in developing fetuses, and potentially have lifelong consequences [29].

As a whole, the studies in farm animals and animal models indicate that PBBs can cause harm. Exposed animals had thyroid, liver and reproductive problems, as well as altered hormone metabolism, and their offspring were also exposed and had developmental problems (Table 1). To determine whether the exposure levels necessary for animals to develop symptoms are comparable with exposure levels reported in humans, the doses can be converted to estimated human equivalents using ratios developed by the Agency for Toxic Substances and Disease Registry based on the average weights of the animals and humans (Figure 2) [30]. However, comparing human equivalents of the animal exposures and human exposures must be done cautiously, because exposure levels in animals were measured in studies as the levels of PBB added to food, whereas the exposure levels reported in humans are measured as the levels currently circulating in the blood. PBB concentration would be expected to be higher in food than the eventual concentration in blood after it had been absorbed through the gut and stored in adipose tissue. The converted animal exposure values would be more comparable to levels of PBB in food consumed by humans.

\section{Effects of PBBs in humans}

A cohort of approximately 5000 exposed individuals from Michigan was established soon after the contamination incident and has been used in many studies evaluating the effects that PBBs. The first studies with this cohort 


\begin{tabular}{|c|c|c|c|c|}
\hline & Cattle & Chickens & Rats & Nonhuman primates \\
\hline Death & $\begin{array}{l}25,000 \mathrm{mg} / \text { day } \\
(262,879 \mathrm{ppm})\end{array}$ & & & \\
\hline Depressed heart rate & $\begin{array}{l}25,000 \mathrm{mg} / \text { day } \\
(262,879 \mathrm{ppm})\end{array}$ & & & \\
\hline Depressed respiratory rate & $\begin{array}{l}25,000 \mathrm{mg} / \text { day } \\
(262,879 \mathrm{ppm})\end{array}$ & & & \\
\hline Perinatal death & & & $\begin{array}{l}100 \mathrm{ppm}^{\dagger} \\
\left(3210 \mathrm{ppm}^{\dagger}\right)\end{array}$ & \\
\hline Miscarriage (hatchability) & $\begin{array}{l}25,000 \mathrm{mg} / \text { day } \\
(262,879 \text { ppm) }\end{array}$ & $\begin{array}{l}45 \mathrm{ppm} \\
\text { (1155 ppm) }\end{array}$ & & $\begin{array}{l}0.3 \mathrm{ppm} \\
(17 \mathrm{ppm})\end{array}$ \\
\hline Decreased fertility & & $\begin{array}{l}45 \mathrm{ppm} \\
(1155 \mathrm{ppm})\end{array}$ & & \\
\hline Decreased milk production & $\begin{array}{l}100 \mathrm{mg} / \text { day } \\
(1051 \mathrm{ppm})\end{array}$ & & & \\
\hline Male genitourinary conditions & $\begin{array}{l}100 \mathrm{mg} / \mathrm{day} \\
(1051 \mathrm{ppm})\end{array}$ & & & \\
\hline Delayed reproductive development & & & $\begin{array}{l}100 \mathrm{ppm}^{\dagger} \\
\left(3210 \mathrm{ppm}^{\dagger}\right)\end{array}$ & \\
\hline Thyroid problems & & & $\begin{array}{l}5 \text { ppm } \\
(160 \mathrm{ppm})\end{array}$ & \\
\hline Weight loss (emaciation) & $\begin{array}{l}25,000 \mathrm{mg} / \text { day } \\
(262,879 \mathrm{ppm})\end{array}$ & $\begin{array}{l}125 \mathrm{ppm} \\
(3210 \mathrm{ppm})\end{array}$ & $\begin{array}{l}200 \mathrm{ppm} \\
(6420 \mathrm{ppm})\end{array}$ & $\begin{array}{l}0.3 \mathrm{ppm} \\
(17 \mathrm{ppm})\end{array}$ \\
\hline Delayed growth & & & $\begin{array}{l}200 \mathrm{ppm} \\
(6420 \mathrm{ppm})\end{array}$ & \\
\hline Enzyme induction & & & $\begin{array}{l}100 \mathrm{ppm}^{\dagger} \\
\left(3210 \mathrm{ppm}^{\dagger}\right)\end{array}$ & \\
\hline Alteration of anesthesia metabolism & & & $\begin{array}{l}10 \mathrm{ppm} \\
(320 \mathrm{ppm})\end{array}$ & \\
\hline Alteration of steroid metabolism & & & $\begin{array}{l}100 \mathrm{ppm}^{\dagger} \\
\left(3210 \mathrm{ppm}^{\dagger}\right)\end{array}$ & \\
\hline Liver problems & $\begin{array}{l}100 \mathrm{mg} / \text { day } \\
(1051 \mathrm{ppm})\end{array}$ & & $\begin{array}{l}10 \mathrm{ppm} \\
(320 \mathrm{ppm})\end{array}$ & $\begin{array}{l}25 \mathrm{ppm} \\
(1452 \mathrm{ppm})\end{array}$ \\
\hline Stomach inflammation & & & & $\begin{array}{l}25 \mathrm{ppm} \\
(1452 \mathrm{ppm})\end{array}$ \\
\hline Skin problems & $\begin{array}{l}100 \mathrm{mg} / \text { day } \\
(1051 \mathrm{ppm})\end{array}$ & & & $\begin{array}{l}0.3 \mathrm{ppm} \\
(17 \mathrm{ppm})\end{array}$ \\
\hline Diarrhea & $\begin{array}{l}25,000 \mathrm{mg} / \text { day } \\
(262,879 \mathrm{ppm})\end{array}$ & & & \\
\hline Excessive salivation & $\begin{array}{l}25,000 \mathrm{mg} / \text { day } \\
(262,879 \mathrm{ppm})\end{array}$ & & & \\
\hline \multicolumn{5}{|c|}{$\begin{array}{l}\text { The level of PBBs fed to various animal models and the health problems that they developed from the exposure. Exposure levels have been converted to the equivalent human } \\
\text { exposure levels using accepted conversion equations. } \\
\text { †Effect seen in offspring of mothers exposed to this level of PBBs. } \\
\text { Data taken from [30]. } \\
\text { PBB: Polybrominated biphenyl. }\end{array}$} \\
\hline
\end{tabular}

began in the late 1970s. On a questionnaire asking about the incidence of health problems, ranging from acne to heart disease, the parents of 292 children who were exposed to PBBs reported a higher prevalence of symptoms in their children than parents of unexposed children from Wisconsin. However, when serum PBB levels were analyzed in these children, it was discovered that the highest number of symptoms were reported in the children who had the lowest serum PBB levels, and that the only complaint that had a positive association with PBB levels was acne in 10-11 year olds [31]. A later study done in both adults and children from the quarantined and nonquarantined farms, as well as the Michigan Chemical Company workers, showed no increase in symptoms in the children from the farms compared with control children in Wisconsin. However, the study did show that adults exposed to PBBs have reported significantly more alopecia, halogen acne, skin peeling and scaling, erythema, itching, increased finger nail growth and increased sweating. It is unclear why adults would experience skin problems when exposed to PBBs and children would not, especially since the children and farmers were both exposed in the same manner [32]. 


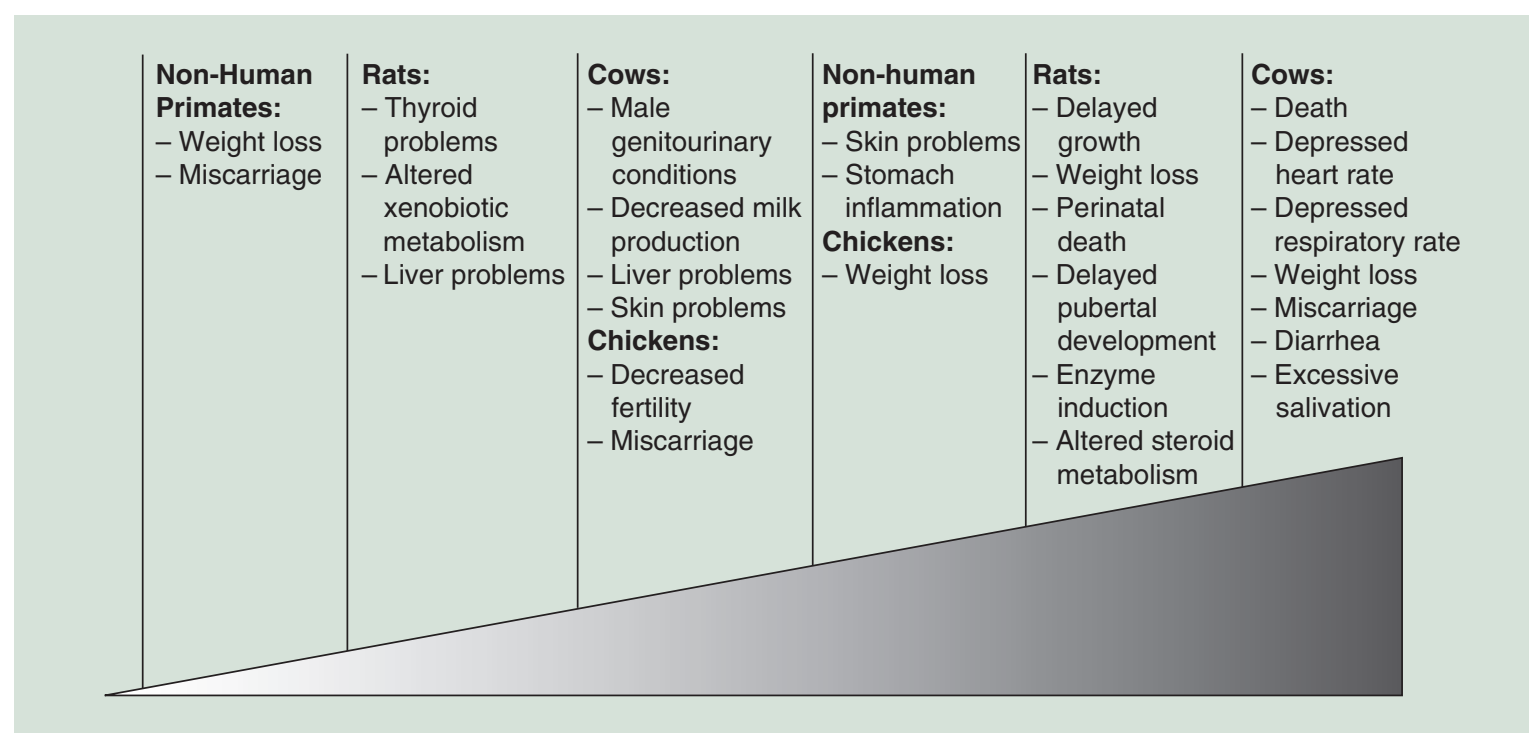

Figure 2. Effects of PBBs on animal models standardized by human equivalent dose.

People in Michigan were concerned with the persistence of PBBs in their bodies. As discussed above, the lipophilic properties PBBs make it likely to persist in humans for years. A study done in 406 women from the cohort determined that the PBB elimination rates in each person were modified by a variety of factors. Higher BMI at enrollment was associated with a slower rate of elimination, and smoking was associated with a faster rate of elimination. The elimination rate was significantly faster if a woman had been pregnant and breastfeeding between serum measurements versus if she had just been pregnant (a decrease of $0.007 \mathrm{ppb} \mathrm{PBB} /$ year if pregnant and breastfeeding vs an increase of $0.008 \mathrm{ppb} \mathrm{PBB} /$ year if just pregnant), although there was not a significant difference compared with women who had never been pregnant. This was surprising given that breastfeeding in animals was shown to be a major elimination route for PBBs but could be due to the mobilization of PBBs from adipose tissue to the bloodstream during physiological changes like pregnancy [33]. Using elimination rates based on these factors, the biological half-life for PBBs in humans was calculated to be between 13 and 29 years, depending on the person's BMI and their initial PBB exposure level [34]. Women who were exposed as children had faster rates of PBB elimination, although that may be related to children having higher PBB serum initially and then undergoing a growth spurt. Additionally, $12 \%$ of the women surveyed showed an increase in PBB serum levels, which remains largely unexplained, unless those subjects somehow had continued exposure even after the contamination clean-up or there was a measurement error [35]. All of these studies were limited because height and weight were only collected at enrollment, not throughout, so any changes in serum PBB levels due to weight changes or growth spurts in children were lost. Furthermore, these studies used only women, making it impossible to assess sex-specific elimination rates and most of the women only had their PBB levels measured twice, making accurate elimination curves difficult.

Even with current measurements of $\mathrm{PBB}$ exposure, studies of thyroid problems gave conflicting results. Initial reports in 35 chemical plant workers showed that $11 \%$ were diagnosed with hypothyroidism and that they had significantly higher levels of thyrotropin, a hormone that regulates the production of other thyroid hormones. However, serum PBB levels were never measured and PBB exposure was assumed based on their employment by the chemical factory, thus the increased prevalence of thyroid problems was unable to be associated with an increased PBB exposure [36]. These results were disputed by a short report in 51 chemical workers, who had an average $\mathrm{PBB}$ level of $12.82 \mathrm{ppm}$, which is substantially more than the average exposure in Michigan. None of these workers reported hypothyroidism or thyroid enlargement, but the report was not explicit with its methods, making it difficult to determine why these two studies conflicted [37]. Further studies in 200 men and women tried to correlate reported thyroid problems with $\mathrm{PBB}$ exposure, but again there was no difference in thyroid disease incidence with levels of PBB exposure [38]. These studies may not have had sufficient sample sizes given the large interpersonal variations in thyroid hormone levels. In the most recent study of 753 individuals from the Michigan PBB registry, it was found that $18 \%$ of participants (and 25\% of women) had thyroid disease, with women exposed 
to higher levels of PBB having increased odds of developing thyroid disease (odds ratio [OR]: 1.12 for any thyroid disease; OR: 2.13 for hypothyroidism). In participants that did not report thyroid disease, there was no association between thyroid hormone levels and PBB exposure levels [39].

A study of cancer risk in individuals exposed to higher levels of PBBs found that, for lymphomas and digestive system cancers, which were grouped to include liver, stomach, esophagus and pancreas, the OR for lymphomas for individuals in the highest exposure group $(>50 \mathrm{ppb})$ versus the lowest exposure group $(<3 \mathrm{ppb})$ was 48.9. For digestive cancers, the OR between exposure groups was 22.9, suggesting that PBB exposure does increase the risk for certain types of cancer [40]. Other studies found that there was an increased risk of breast cancer in people exposed to higher levels of PBB, but it did not reach statistical significance [41,42]. Recently, PBBs have been reclassified from a possible (Group 2B) to a probable (Group 2A) human carcinogen by the International Agency for Research on Cancer.

Given that animal studies had shown reproductive delay in rats exposed to PBBs, research was done to determine whether there was an increased incidence of reproductive disorders. Studies conducted to date have not identified an association between PBB exposure and incidence of endometriosis [43] or risk of spontaneous abortion [44]. PBB exposure was also not associated with a risk of an abnormal pap test result [45]. However, these studies were all conducted in individuals that were directly exposed to PBBs.

Importantly, the effects of PBBs are not limited to those originally exposed, because PBBs are transmitted to the children of exposed mothers. As in the animal models, PBBs in humans can be passed through the placenta and through breast milk. Umbilical cord blood serum was found to have about a third the PBB concentration of the maternal blood serum, but breast milk was found to have 100-times the concentration of PBBs [46,47]. Additionally, infants breastfed by exposed mothers for 6 months were six-times more likely to have detectable levels of PBBs in their blood than babies who were born to exposed mothers but not breastfed [47]. Thus, there is substantial evidence of intergenerational transmission of $\mathrm{PBBs}$ and that infants born to exposed mothers are exposed during critical developmental periods.

Research then assessed the health effects in the second generation. One study reported a higher percentage of boys born to the exposed cohort (54.2\%), though this difference was not statistically significant [48]. Another study found no significant association between either infant birth weight or gestational age and maternal PBB exposure [49]. However, a further study in this cohort did report that babies born to mothers exposed to high levels of PBBs had higher birth weight (an increase of $16 \mathrm{~g}$ per $10 \mathrm{ppb}$ exposure in the mother), but only if the mothers were exposed before puberty [50]. This was further confirmed by offspring of mothers with even lower PBB exposure (blood serum above $1 \mathrm{ppb}$ ) having three-times the odds of having lower Apgar scores, but again, only if the mothers were exposed to prior to the start of puberty (age of exposure was $<10$ years old) [51]. Thus, more nuanced approaches to how PBBs affect exposed individuals and their offspring need to be implemented, and the dosage, duration and time point of the exposure need to be considered.

Because the Michigan PBB registry has been tracking the exposed cohort for over 40 years now, it has also been possible to study the effects of $\mathrm{PBB}$ exposure on adults who were exposed in utero and through breastfeeding. Men born to highly exposed mothers were three-times as likely to report any genitourinary condition, like hernias or hydroceles (OR: 3.1) [52]. Women born to highly exposed mothers had an earlier age of menarche and an earlier age at pubic hair development (11.6 vs 12.7 years old). While there was no change in the timing of breast development (as measured by the Tanner Stage criteria) in this same study, this may be due to the difficulty of the girls assessing their own breast development based on pictures [53]. The daughters of highly exposed mothers had a higher OR for spontaneous abortions (OR: 4.08), although they did not have any trouble with conceiving children [54]. Taken together, this suggests that there may be certain windows of vulnerability during human development, making children of exposed parents more susceptible to adverse health outcomes from the endocrine-disrupting action of PBBs. While the individuals who were directly exposed in the 1970s report a variety of health problems ranging from skin problems to cancer, their children report more reproductive and developmental conditions (Figure 3).

\section{Epigenetic effects of PBB exposure}

While great progress has been made over the past 40 years to determine the health effects of PBB exposure, there are still many research questions that remain unanswered. It is unclear at this time why some of the symptoms and conditions reported more frequently by the individuals in the Michigan cohort do not seem to depend on the concentration of PBBs in their blood, although the difficulty in calculating the appropriate target organ's dose of $\mathrm{PBB}$ may contribute to this problem. Additionally, while children of exposed individuals might have more 


\begin{tabular}{|l|l|l|}
\hline Symptoms reported & $\begin{array}{l}\text { Before } \\
\mathbf{1 9 7 3}\end{array}$ & $\begin{array}{l}\text { After } \\
\mathbf{1 9 7 3}\end{array}$ \\
\hline Alopecia & & \\
\hline Skin problems & & \\
\hline Finger nail growth & & \\
\hline Sweating & & \\
\hline Thyroid problems & & \\
\hline Cancer & & \\
\hline Spontaneous abortion & & \\
\hline Offspring with higher birth weight & & \\
\hline Offspring with lower Apgar score & & \\
\hline Male genitourinary conditions & & \\
\hline Lower age of menarche & \\
\hline
\end{tabular}

Figure 3. Summary of significant findings in Michigan polybrominated biphenyl registry.

reproductive problems than their parents did due to developmental windows of vulnerability, this hypothesis is not fully tested, and it is not known which effects are sensitive to particular developmental periods. Furthermore, the mechanism by which PBB exposure causes health problems is not fully understood.

Changes in epigenetic marks have been linked to the development of many diseases, including those reported by the people in the Michigan PBB registry. Disorders associated with changes in epigenetic marks include many types of cancers, neurological problems, autoimmune disease and reproductive problems [55-57]. If PBB does influence epigenetic regulation of genes, that could provide a mechanism to explain the increased number of health problems experienced by the people in Michigan.

Currently, no research examining epigenetic differences associated with $\mathrm{PBB}$ exposure has been reported, either in animal models or in humans. Therefore, hypotheses on how PBB could affect the epigenome have to rely on studies in other EDCs. Because PBBs have a chemical structure that is similar to PCBs and polybrominated diphenyl ethers (PBDEs), PBBs are most comparable with these molecules. Additionally, exposure to PCBs and PBDEs are associated with many of the same health problems as exposure to PBBs, such as increased risk for reproductive problems, issues with steroid hormone metabolism and thyroid problems [58-71]. Because PBBs, PCBs and PBDEs share the same adverse health outcomes and are structurally similar, studies on how PCBs and PBDEs affect epigenetic marks are currently the best tool to understanding how PBBs affect the epigenome.

Research in EDCs show global changes in DNA methylation, histone methylation, gene expression and cellular function. Both human and mouse cell lines that were exposed to micromolar quantities ( $\sim 0.6 \mathrm{ppm}$ ) of PBDEs and PCBs showed significant decreases in global DNA methylation levels and increases in adipocyte differentiation, potentially explaining the epidemiological studies linking exposure to these EDCs to increased obesity in adulthood [72]. Additionally, in a human vascular endothelial cell line exposed to 0.3 to $3 \mathrm{nM}$ of PCBs ( 0.09-0.9 ppb), exposure activated demethylation of histone $\mathrm{H} 3$ lysine 9 (H3K9), which then caused 140-200\% increase in expression of inflammatory genes (vs controls) [73]. Studies with bisphenol A (BPA), another EDC, showed that breast epithelial cell lines that were exposed to BPA had increased activation of the estrogen signaling pathway, which then led to the suppression of 170 different genes and increased levels of DNA methylation across the genome. The author suggested that the epigenetic changes and increased estrogen activity could explain why exposure to BPA increases the risk of breast cancer development [74]. Another study reported that EDCs induce estrogen signaling pathways, both through the estrogen receptor's transcription factor activity and through the estrogen receptor's activation of other signaling pathways. Additionally, this study found that EDCs activate the PI3K/AKT pathway, which results in the inactivation of EZH2, a histone methyltransferase. EDCs can also bind the members of the nuclear hormone receptor superfamily, and thus activate the MAPK signaling pathway, which can influence cell growth, apoptosis, differentiation and motility, potentially explaining why exposure to EDCs during early developmental windows disrupts organogenesis and reduces fecundity and sperm motility [75]. Taken together, EDCs 
can directly change the epigenetic state of a cell, the transcriptional profile of a cell and that cell's function, which could lead to the health problems seen in exposed populations.

In one of the first studies investigating persistent organic pollutants and DNA methylation in humans, PCB exposure was associated with global DNA hypomethylation in a cohort of 71 highly exposed individuals from Greenland [76]. Another study in 86 Koreans with population-level exposure to PCBs also found global DNA hypomethylation with increasing exposure level [77]. In a study of 524 elderly people in Sweden, however, increasing PCB exposure was associated with global DNA hypermethylation [78]. While it is not clear why in some populations EDC exposure is associated with DNA hypermethylation and in others it is associated with DNA hypomethylation, these conflicting results may be due to the different studies using different methods to estimate global DNA methylation levels, differences in the populations, differences in the dose of the exposure or differences in the timing of exposure. Therefore, while exposure to EDCs appears to associate with differences in global DNA methylation, more studies are needed to determine the precise relationship. Additionally, because these global DNA methylation studies only examine methylation in repetitive, gene-poor regions of the genome, genome-wide studies looking at differences in methylation level at CpGs near genes are needed, as well as studies evaluating epigenetics as a mediator between exposure and the health outcomes reported by exposed humans.

PCBs have been shown to bind to nuclear receptors and change gene expression, and to associate with differences in DNA methylation levels in human populations that have been exposed. Presumably, PBBs can also bind to nuclear receptors on DNA and drive gene expression, that gene expression may be associated with differences in the epigenetic marks and in cellular function. These differences would be more pronounced with higher exposure levels [69].

From the animal and human studies, PBBs pass through the placental barrier and are present in breast milk - exposing children born to exposed mothers and leading to health problems in offspring that were not seen in the exposed parents [46,47,51-54]. Altered gene regulation and expression early in development could explain why the children of those exposed have more health problems than their parents. Precise epigenetic patterns are vitally important during embryonic development because the specific timing of gene activation and repression determines cell differentiation and organogenesis. Additionally, because epigenetic marks need to change, and to change precisely, for an embryo to develop, these marks may be particularly susceptible to disturbances. Disruption of epigenetic signals by PBBs crossing the placenta could cause improper development or permanently altered marks that would cause life-long problems [79]. A study done with placentas from the National Children's Study found that PBDEs and PCBs increased DNA methylation in the placenta at imprinted loci. PCB exposure was also negatively associated with $H 19$ expression, which is important for proper regulation fetal growth [80]. Children who were exposed early in development would be more susceptible to epigenetic alterations due to their epigenetic marks changing and their cell lineages still being determined. This could then lead to an increased risk of developmental and chronic diseases throughout life. Furthermore, while it has not been demonstrated in a human population exposed to EDCs, there have been a report in animal models exposed to EDCs of epigenetic marks escaping mammalian reprogramming events that happen early in development. In this study, the epigenetic marks that associated with environmental exposure were said to be transmitted to offspring even when the offspring was not exposed to the chemical itself [81]. If this is the case, then the children of exposed men would also be at risk, as well as the children of exposed women.

\section{Genetics of PBB exposure}

Another way there could be an intergenerational pattern of adverse health effects following chemical exposure would be through families being exposed to both similar environments and transmitting genetic material from parent to child. The health effects following PBB exposure will most likely depend on the genetic architecture of the population and individual exposed. Two people could be exposed to the same chemical, at the same level, in the same manner, at the same age and have different health outcomes due to genetic variation. For example, one study found that the length of the CAG repeat in exon 1 of $A R$, which varies in the population and the alters the transcriptional activity of $A R$, mediated the reproductive outcomes associated with exposure to PCB. Men with fewer than 20 CAG repeats who were exposed to PCB above the median exposure level had a $42 \%$ decrease in sperm count and a 35\% decrease in sperm concentration. Moreover, the authors found that if they did not account for the number of CAG repeats that no association was found between sperm concentration or count and PCB exposure level [82]. Another study found that both the CAG and the GGN repeat length polymorphisms in exon 1 of the $A R$ gene modified the association between EDCs and the proportion of $Y$ bearing sperm, and this 
association was more pronounced if the men also had a common SNP (rs2292596) in AHRR that made it less able to repress $A H R$ [83]. Common variants that mediate the stability of the $A H R$ gene and the repressing function of the $A H R R$ gene also mediate the association between EDCs, including PCBs, and reproductive function [84]. Differences in genes related to steroid-hormone and xenobiotic pathways may explain why many health outcomes only associate with exposure to EDCs in some populations, and the difficulty that studies have in finding an association between the exposure dose and health outcomes [85,86]. Therefore, the difficulty in associating health outcomes to exposure levels in the Michigan PBB cohort may be resolved by accounting for variation in genetic structure. Additionally, genetic variation can impact epigenetic variation and disease susceptibility. For example, methylation quantitative trait loci are genetic variants where the genotype at that locus results in differing patterns of DNA methylation [87]. Methylation quantitative trait loci are associated with the development and progression of many human diseases $[88,89]$. Therefore, some individuals may be more likely to experience epigenetic alterations following EDC exposure. Understanding genetic susceptibility will aid in identifying health risks in parents and their children exposed to EDCs.

\section{Future perspective}

The Michigan PBB registry is an active cohort and the community is involved in investigating their continuing health risks. Despite the predominant exposure having occurred over 40 years ago, PBBs are highly lipophilic and bioaccumulative, meaning that exposure and its consequences to the population continues long after the resolution of the initial contamination event [7]. PBBs are able to pass through the placental barrier and are present in breast milk and are thus able to expose future generations. Therefore, people are still at risk from PBB exposure.

While studies in animal models are highly informative for guiding epidemiological investigations, it is difficult to translate knowledge from early studies of animal models to humans because of the differences in quantifying PBB exposure between the two experimental designs. Specifically, most PBB studies in animals report the amount of PBB added to the animal's diet instead of measuring PBB levels in blood and other tissues assayed in humans. Animal studies also rarely assess exposure levels in the offspring of exposed animals. As PBB exposure remains an active public health issue in Michigan, additional studies of animal models exposed to PBBs will provide more precise information regarding the effects of $\mathrm{PBB}$ exposure and additional insight into the mechanisms underlying intergeneration transmission of health consequences from exposure.

To enable a better understanding of the health risks to those exposed and subsequent generations, epigenetic and genetic data should be collected in longitudinal cohorts like the Michigan PBB registry. The addition of these datasets to well-studied epidemiological cohorts will allow future studies to better investigate the effects of EDCs on human health. Identification of genes whose function differ in response to PBB exposure will increase understanding of how PBB contributes to health problems. Because the Michigan PBB registry has been followed for 40 years and is adding subsequent generations of those originally exposed, investigating epigenetic and genetic associations will lead to a greater understanding of the biological mechanisms behind the intergenerational transmission of exposure-related health effects and help to determine the health risks for future generations. Results from this cohort can be used to help guide studies on other types of EDCs and exposures and to determine if there is a safe exposure level to EDCs for humans.

\section{Executive summary}

- Endocrine-disrupting compounds (EDCs) are a growing concern for the modern world, and multigenerational cohorts are needed to study it further.

- The Michigan polybrominated biphenyl registry is a multigenerational cohort who were exposed to an EDC 40 years ago during an agricultural accident and have been followed since.

- Existing studies in this cohort show an intergenerational transmission of exposure-related health problems.

- Genetic and epigenetic studies of health problems in the Michigan polybrominated biphenyl registry may lead to a greater understanding of the mechanisms behind intergenerational transmission of EDCs and the risk to future generations.

\section{Acknowledgements}

We are grateful to the members of the Michigan PBB registry for their participation and engagement with research studies over the past 40 years. 
Financial \& competing interests disclosure

This work was supported by the National Institute of Environmental Health Sciences (NIEHS; 5R01ES024790, 5R01ES025775) and the National Institute of General Medical Sciences (T32GM008490). The authors declare they have no actual or potential competing financial interest. The authors have no other relevant affiliations or financial involvement with any organization or entity with a financial interest in or financial conflict with the subject matter or materials discussed in the manuscript apart from those disclosed. No writing assistance was utilized in the production of this manuscript.

\section{Open access}

This work is licensed under the Attribution-NonCommercial-NoDerivatives 4.0 Unported License. To view a copy of this license, visit http://creativecommons.org/licenses/by-nc-nd/4.0/

\section{References}

Papers of special note that have been highlighted as: $\bullet$ of interest; $\bullet \bullet$ of considerable interest

1. Fromme H, Hilger B, Kopp E, Miserok M, Volkel W. Polybrominated diphenyl ethers (PBDEs), hexabromocyclododecane (HBCD) and "novel" brominated flame retardants in house dust in Germany. Environ. Int. 64, 61-68 (2014).

2. Nassar N, Abeywardana P, Barker A, Bower C. Parental occupational exposure to potential endocrine disrupting chemicals and risk of hypospadias in infants. Occup. Environ. Med. 67(9), 585-589 (2010).

3. Mahalingam S, Ther L, Gao L, Wang W, Ziv-Gal A, Flaws JA. The effects of in utero bisphenol A exposure on ovarian follicle numbers and steroidogenesis in the F1 and F2 generations of mice. Reprod. Toxicol. 74, 150-157 (2017).

4. Tournaire M, Epelboin S, Devouche E et al. Adverse health effects in children of women exposed in utero to diethylstilbestrol (DES). Therapie 71(4), 395-404 (2016).

5. Titus-Ernstoff L, Troisi R, Hatch EE et al. Birth defects in the sons and daughters of women who were exposed in utero to diethylstilbestrol (DES). Int. J. Androl. 33(2), 377-384 (2010).

6. Agency for Toxic Substances and Disease Registry. Toxological profile for polybrominated biphenyl (2004). https://www.atsdr.cdc.gov/toxprofiles/tp68.pdf

7. Fries GF. The PBB episode in Michigan: an overall appraisal. Crit. Rev. Toxicol. 16(2), 105-156 (1985).

8. Kay K. Polybrominated biphenyls (PBB) environmental contamination in Michigan, 1973-1976. Environ. Res.13(1), 74-93 (1977).

9. Jackson TF, Halbert FL. A toxic syndrome associated with the feeding of polybrominated biphenyl-contaminated protein concentrate to dairy cattle. J. Am. Vet. Med. Assoc. 165(5), 437-439 (1974).

10. Cook H, Helland DR, Vanderweele BH, Dejong RJ. Histotoxic effects of polybrominated biphenyls in Michigan dairy cattle. Environ. Res. 15(1), 82-89 (1978).

11. Wolff MS, Aubrey B. PBB homologs in sera of Michigan dairy farmers and Michigan chemical workers. Environ. Health Perspect. 23, 211-215 (1978).

12. Durst HI, Willett LB, Schanbacher FL, Moorhead PD. Effects of PBBs on cattle. I. Clinical evaluations and clinical chemistry. Environ. Health Perspect. 23, 83-89 (1978).

13. Robl MG, Jenkins DH, Wingender RJ, Gordon DE. Toxicity and residue studies in dairy animals with firemaster FF-1 (polybrominated biphenyls). Environ. Health Perspect. 23, 91-97 (1978).

14. Willett LB, Durst HI. Effects of PBBs on cattle. IV. Distribution and clearance of components of firemaster BP-6. Environ. Health Perspect. 23, 67-74 (1978).

15. Polin D, Ringer RK. PBB fed to adult female chickens: its effect on egg production, reproduction, viability of offspring, and residues in tissues and eggs. Environ. Health Perspect. 23, 283-290 (1978).

16. Mccormack KM, Melrose P, Rickert DE, Dent JG, Gibson JE, Hook JB. Concomitant dietary exposure to polychlorinated biphenyls and polybrominated biphenyls: tissue distribution and arylhydrocarbon hydroxylase activity in lactating rats. Toxicol. Appl. Pharmacol. 47(1), 95-104 (1979).

17. Rickert DE, Dent JG, Cagen SZ, McCormack KM, Melrose P, Gibson JE. Distribution of polybrominated biphenyls after dietary exposure in pregnant and lactating rats and their offspring. Environ. Health Perspect. 23, $63-66$ (1978).

18. Harris SJ, Cecil HC, Bitman J. Embryotoxic effects of polybrominated biphenyls (PBB) in rats. Environ. Health Perspect. 23, 295-300 (1978).

19. Mccormack KM, Lepper LF, Wilson DM, Hook JB. Biochemical and physiological sequelae to perinatal exposure to polybrominated biphenyls: a multigeneration study in rats. Toxicol. Appl. Pharmacol. 59(2), 300-313 (1981).

20. McCormack KM, Braselton WE Jr, Sanger VL, Hook JB. Residual effects of polybrominated biphenyls following perinatal exposure in rats. Toxicol. Appl. Pharmacol. 53(1), 108-115 (1980). 
21. Dent JG, McCormack KM, Rickert DE, Cagen SZ, Melrose P, Gibson JE. Mixed function oxidase activities in lactating rats and their offspring following dietary exposure to polybrominated biphenyls. Toxicol. Appl. Pharmacol. 46(3), 727-735 (1978).

22. Dent JG. Characteristics of cytochrome P-450 and mixed function oxidase enzymes following treatment with PBBs. Environ. Health Perspect. 23, 301-307 (1978).

23. Dannan GA, Moore RW, Besaw LC, Aust SD. 2,4,5,3',4',5'-Hexabromobiphenyl is both a 3-methylcholanthrene-and a phenobarbital-type inducer of microsomal drug metabolizing enzymes. Biochem. Biophys. Res. Commun. 85(1), 450-458 (1978).

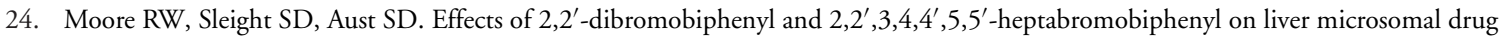
metabolizing enzymes. Toxicol. Appl. Pharmacol. 48(1 Pt 1), 73-86 (1979).

25. Byrne JJ, Carbone JP, Hanson EA. Hypothyroidism and abnormalities in the kinetics of thyroid hormone metabolism in rats treated chronically with polychlorinated biphenyl and polybrominated biphenyl. Endocrinology 121(2), 520-527 (1987).

26. Arneric SP, McCormack KM, Braselton WE Jr, Hook JB. Altered metabolism of progesterone by hepatic microsomes from rats following dietary exposure to polybrominated biphenyls. Toxicol. Appl. Pharmacol. 54(2), 187-196 (1980).

27. Newton JF, Braselton WE Jr, Lepper LF, McCormack KM, Hook JB. Effects of polybrominated biphenyls on metabolism of testosterone by rat hepatic microsomes. Toxicol. Appl. Pharmacol. 63(1), 142-149 (1982).

28. Lambrecht LK, Barsotti DA, Allen JR. Responses of nonhuman primates to a polybrominated biphenyl mixture. Environ. Health Perspect. 23, 139-145 (1978).

29. Ibhazehiebo K, Iwasaki T, Okano-Uchida T, Shimokawa N, Ishizaki Y, Koibuchi N. Suppression of thyroid hormone receptor-mediated transcription and disruption of thyroid hormone-induced cerebellar morphogenesis by the polybrominated biphenyl mixture, BP-6. Neurotoxicology 32(4), 400-409 (2011).

30. Agency for Toxic Substances and Disease Registry. EPA reportable quantity methodology used to establish toxicity/environmental scores for the Substance Priority List. https://www.atsdr.cdc.gov/spl/resources/atsdr_tes_methodology.pdf

31. Barr M Jr. Pediatric aspects of the Michigan polybrominated biphenyl contamination. Environ. Res. 21(2), 255-274 (1980).

32. Chanda JJ, Anderson HA, Glamb RW et al. Cutaneous effects of exposure to polybrominated biphenyls (PBBs): the Michigan PBB incident. Environ. Res. 29(1), 97-108 (1982).

33. Terrell ML, Manatunga AK, Small CM et al. A decay model for assessing polybrominated biphenyl exposure among women in the Michigan long-term PBB study. J. Expo. Sci. Environ. Epidemiol. 18(4), 410-420 (2008).

34. Blanck HM, Marcus M, Hertzberg V et al. Determinants of polybrominated biphenyl serum decay among women in the Michigan PBB cohort. Environ. Health Perspect. 108(2), 147-152 (2000).

35. Sweeney AM, Symanski E, Burau KD, Kim YJ, Humphrey HE, Smithci MA. Changes in serum PBB and PCB levels over time among women of varying ages at exposure. Environ. Res. 86(2), 128-139 (2001).

36. Bahn AK, Mills JL, Snyder PJ et al. Hypothyroidism in workers exposed to polybrominated biphenyls. N. Engl. J. Med. 302(1), 31-33 (1980).

37. Stross JK. Hypothyroidism and polybrominated biphenyls. N. Engl. J. Med. 302(25), 1421 (1980).

38. Yard EE, Terrell ML, Hunt DR et al. Incidence of thyroid disease following exposure to polybrominated biphenyls and polychlorinated biphenyls, Michigan, 1974-2006. Chemosphere 84(7), 863-868 (2011).

39. Jacobson MH, Darrow LA, Barr DB et al. Polybrominated biphenyls and polychlorinated biphenyls (PBBs and PCBs) and thyroid function in a cohort of Michigan adults, 2004-2015. (In Press).

40. Hoque A, Sigurdson AJ, Burau KD, Humphrey HE, Hess KR, Sweeney AM. Cancer among a Michigan cohort exposed to polybrominated biphenyls in 1973. Epidemiology 9(4), 373-378 (1998).

41. Henderson AK, Rosen D, Miller GL et al. Breast cancer among women exposed to polybrominated biphenyls. Epidemiology 6(5), 544-546 (1995).

42. Terrell ML, Rosenblatt KA, Wirth J, Cameron LL, Marcus M. Breast cancer among women in Michigan following exposure to brominated flame retardants. Occup. Environ. Med. 73(8), 564-567 (2016).

43. Hoffman CS, Small CM, Blanck HM, Tolbert P, Rubin C, Marcus M. Endometriosis among women exposed to polybrominated biphenyls. Ann. Epidemiol. 17(7), 503-510 (2007).

44. Small CM, Cheslack-Postava K, Terrell M et al. Risk of spontaneous abortion among women exposed to polybrominated biphenyls. Environ. Res. 105(2), 247-255 (2007)

45. Jamieson DJ, Terrell ML, Aguocha NN, Small CM, Cameron LL, Marcus M. Dietary exposure to brominated flame retardants and abnormal Pap test results. J. Womens Health (Larchmt) 20(9), 1269-1278 (2011).

46. Jacobson JL, Fein GG, Jacobson SW, Schwartz PM, Dowler JK. The transfer of polychlorinated biphenyls (PCBs) and polybrominated biphenyls (PBBs) across the human placenta and into maternal milk. Am. J. Public Health 74(4), 378-379 (1984).

47. Joseph AD, Terrell ML, Small CM, Cameron LL, Marcus M. Assessing inter-generational transfer of a brominated flame retardant. J. Environ. Monit. 11(4), 802-807 (2009).

- Polychlorinated biphenyls are transferred intergenerationally through placental passage and breastfeeding. 
48. Terrell ML, Berzen AK, Small CM, Cameron LL, Wirth JJ, Marcus M. A cohort study of the association between secondary sex ratio and parental exposure to polybrominated biphenyl (PBB) and polychlorinated biphenyl (PCB). Environ. Health 8, 35 (2009).

49. Givens ML, Small CM, Terrell ML et al. Maternal exposure to polybrominated and polychlorinated biphenyls: infant birth weight and gestational age. Chemosphere 69(8), 1295-1304 (2007).

50. Sweeney AM, Symanski E. The influence of age at exposure to PBBs on birth outcomes. Environ. Res. 105(3), 370-379 (2007).

51. Terrell ML, Hartnett KP, Lim H, Wirth J, Marcus M. Maternal exposure to brominated flame retardants and infant Apgar scores. Chemosphere 118, 178-186 (2015).

52. Small CM, Decaro JJ, Terrell ML et al. Maternal exposure to a brominated flame retardant and genitourinary conditions in male offspring. Environ. Health Perspect. 117(7), 1175-1179 (2009).

-• Development effects that an endocrine-disrupting compound (EDC) can have on males exposed in utero.

53. Blanck HM, Marcus M, Tolbert PE et al. Age at menarche and tanner stage in girls exposed in utero and postnatally to polybrominated biphenyl. Epidemiology 11(6), 641-647 (2000).

-• Reproductive effects of an EDC on daughters of women exposed - effects that were not seen in the mothers themselves.

54. Small CM, Murray D, Terrell ML, Marcus M. Reproductive outcomes among women exposed to a brominated flame retardant in utero. Arch. Environ. Occup. Health 66(4), 201-208 (2011).

55. Portela A, Esteller M. Epigenetic modifications and human disease. Nat. Biotechnol. 28(10), 1057-1068 (2010).

56. Hasham A, Tomer Y. Genetic and epigenetic mechanisms in thyroid autoimmunity. Immunol. Res. 54(1-3), 204-213 (2012).

57. Dyson MT, Roqueiro D, Monsivais D et al. Genome-wide DNA methylation analysis predicts an epigenetic switch for GATA factor expression in endometriosis. PLoS Genet. 10(3), e1004158 (2014).

58. Allen JG, Gale S, Zoeller RT, Spengler JD, Birnbaum L, McNeely E. PBDE flame retardants, thyroid disease, and menopausal status in U.S. women. Environ. Health 15(1), 60 (2016).

59. Frederiksen M, Vorkamp K, Thomsen M, Knudsen LE. Human internal and external exposure to PBDEs - a review of levels and sources. Int. J. Hyg. Environ. Health 212(2), 109-134 (2009).

60. Canton RF, Sanderson JT, Nijmeijer S, Bergman A, Letcher RJ, Van Den Berg M. In vitro effects of brominated flame retardants and metabolites on CYP17 catalytic activity: a novel mechanism of action? Toxicol. Appl. Pharmacol. 216(2), 274-281 (2006).

61. Miller VM, Sanchez-Morrissey S, Brosch KO, Seegal RF. Developmental coexposure to polychlorinated biphenyls and polybrominated diphenyl ethers has additive effects on circulating thyroxine levels in rats. Toxicol. Sci. 127(1), 76-83 (2012).

62. Costa LG, Giordano G. Developmental neurotoxicity of polybrominated diphenyl ether (PBDE) flame retardants. Neurotoxicology 28(6), 1047-1067 (2007).

63. Legler J, Brouwer A. Are brominated flame retardants endocrine disruptors? Environ. Int. 29(6), 879-885 (2003).

64. Herbstman JB, Sjodin A, Kurzon M et al. Prenatal exposure to PBDEs and neurodevelopment. Environ. Health Perspect. 118(5), 712-719 (2010).

65. Messer A. Mini-review: polybrominated diphenyl ether (PBDE) flame retardants as potential autism risk factors. Physiol. Behav. 100(3), 245-249 (2010).

66. Chevrier J, Harley KG, Bradman A, Gharbi M, Sjodin A, Eskenazi B. Polybrominated diphenyl ether (PBDE) flame retardants and thyroid hormone during pregnancy. Environ. Health Perspect. 118(10), 1444-1449 (2010).

67. Safe S. Polychlorinated biphenyls (PCBs) and polybrominated biphenyls (PBBs): biochemistry, toxicology, and mechanism of action. Crit. Rev. Toxicol. 13(4), 319-395 (1984).

68. Safe SH. Polychlorinated biphenyls (PCBs): environmental impact, biochemical and toxic responses, and implications for risk assessment. Crit. Rev. Toxicol. 24(2), 87-149 (1994).

69. Giera S, Bansal R, Ortiz-Toro TM, Taub DG, Zoeller RT. Individual polychlorinated biphenyl (PCB) congeners produce tissue- and gene-specific effects on thyroid hormone signaling during development. Endocrinology 152(7), 2909-2919 (2011).

70. Hisada A, Shimodaira K, Okai T et al. Associations between levels of hydroxylated PCBs and PCBs in serum of pregnant women and blood thyroid hormone levels and body size of neonates. Int. J. Hyg. Environ. Health 217(4-5), 546-553 (2014).

71. Jacobson JL, Jacobson SW. Dose-response in perinatal exposure to polychlorinated biphenyls (PCBs): the Michigan and North Carolina cohort studies. Toxicol. Ind. Health 12(3-4), 435-445 (1996).

72. Bastos Sales L, Kamstra JH, Cenijn PH, Van Rijt LS, Hamers T, Legler J. Effects of endocrine disrupting chemicals on in vitro global DNA methylation and adipocyte differentiation. Toxicol. In Vitro 27(6), 1634-1643 (2013).

73. Liu D, Perkins JT, Petriello MC, Hennig B. Exposure to coplanar PCBs induces endothelial cell inflammation through epigenetic regulation of NF-kappaB subunit p65. Toxicol. Appl. Pharmacol. 289(3), 457-465 (2015).

74. Weng YI, Hsu PY, Liyanarachchi S et al. Epigenetic influences of low-dose bisphenol A in primary human breast epithelial cells. Toxicol. Appl. Pharmacol. 248(2), 111-121 (2010). 
75. Wong RL, Walker CL. Molecular pathways: environmental estrogens activate nongenomic signaling to developmentally reprogram the epigenome. Clin. Cancer Res. 19(14), 3732-3737 (2013).

76. Rusiecki JA, Baccarelli A, Bollati V, Tarantini L, Moore LE, Bonefeld-Jorgensen EC. Global DNA hypomethylation is associated with high serum-persistent organic pollutants in Greenlandic Inuit. Environ. Health Perspect. 116(11), 1547-1552 (2008).

-. One of the first studies showing that DNA methylation associates with polychlorinated biphenyl exposure in a human population.

77. Kim KY, Kim DS, Lee SK et al. Association of low-dose exposure to persistent organic pollutants with global DNA hypomethylation in healthy Koreans. Environ. Health Perspect. 118(3), 370-374 (2010).

78. Lind L, Penell J, Luttropp K et al. Global DNA hypermethylation is associated with high serum levels of persistent organic pollutants in an elderly population. Environ. Int. 59, 456-461 (2013).

79. Marsit CJ. Influence of environmental exposure on human epigenetic regulation. J. Exp. Biol. 218(Pt 1), 71-79 (2015).

-• An excellent review of how environmental contaminants can alter epigenetic regulation of genes.

80. Kappil MA, Li Q, Li A et al. In utero exposures to environmental organic pollutants disrupt epigenetic marks linked to fetoplacental development. Environ. Epigenet. 2(1) (2016).

81. Anway MD, Cupp AS, Uzumcu M, Skinner MK. Epigenetic transgenerational actions of endocrine disruptors and male fertility. Science 308(5727), 1466-1469 (2005).

82. Giwercman A, Rylander L, Rignell-Hydbom A et al. Androgen receptor gene CAG repeat length as a modifier of the association between persistent organohalogen pollutant exposure markers and semen characteristics. Pharmacogenet. Genomics 17(6), 391-401 (2007).

83. Tiido T, Rignell-Hydbom A, Jonsson BA, Rylander L, Giwercman A, Giwercman YL. Modifying effect of the AR gene trinucleotide repeats and SNPs in the AHR and AHRR genes on the association between persistent organohalogen pollutant exposure and human sperm Y:X ratio. Mol. Hum. Reprod. 13(4), 223-229 (2007).

84. Brokken LJ, Lundberg PJ, Spano $\mathrm{M}$ et al. Interactions between polymorphisms in the aryl hydrocarbon receptor signalling pathway and exposure to persistent organochlorine pollutants affect human semen quality. Reprod. Toxicol. 49, 65-73 (2014).

- A study in a human population that showed how genetic variability influenced endocrine response to EDCs.

85. Toft G, Axmon A, Lindh CH, Giwercman A, Bonde JP. Menstrual cycle characteristics in European and Inuit women exposed to persistent organochlorine pollutants. Hum. Reprod. 23(1), 193-200 (2008).

86. Jonsson $\mathrm{BA}$, Rylander $\mathrm{L}$, Lindh $\mathrm{C}$ et al. Inter-population variations in concentrations, determinants of and correlations between

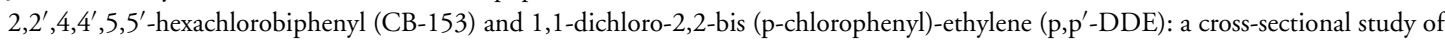
3161 men and women from Inuit and European populations. Environ. Health 4, 27 (2005).

87. Smith AK, Kilaru V, Kocak M et al. Methylation quantitative trait loci (meQTLs) are consistently detected across ancestry, developmental stage, and tissue type. BMC Genomics 15, 145 (2014).

88. Bonder MJ, Luijk R, Zhernakova DV et al. Disease variants alter transcription factor levels and methylation of their binding sites. Nat. Genet. 49(1), 131-138 (2017).

89. Jaffe AE, Gao Y, Deep-Soboslay A et al. Mapping DNA methylation across development, genotype and schizophrenia in the human frontal cortex. Nat. Neurosci. 19(1), 40-47 (2016). 